\title{
Guerra y paz durante el gobierno del presidente Numeiri en Sudán
}

\section{War and Peace in Sudan during the Government of President Nimeiry}

\section{ALFREDO LANGA HERRERO*}

Resumen: En este artículo se analiza el gobierno presidido por Yaafar Mohamed al Numeiri (1969-1985) en la República de Sudán desde el punto de vista de la evolución de los conflictos armados en el país y las iniciativas de paz impulsadas en ese tiempo. Con un enfoque histórico, se examina el triunfo de la Revolución de Mayo y las grandes expectativas de cambio creadas dentro y fuera del país, así como las fases por las que pasó el liderazgo de Numeiri y su transformación de líder socialista en líder islamista. Se hace hincapié en las consecuencias de dicha transformación y del malogrado proceso de descentralización en el escenario de conflicto, sobre todo respecto al sur del país.

Palabras clave: guerra; paz; Sudán; Numeiri; Sudán del Sur.

Abstract: This article analyses the government of President Gaafar Muhammad al-Nimeiry (1969-1985) in the Republic of Sudan, taking into account the evolution of armed conflicts in the country as well as peace initiatives launched during this period. From a historical point of view, it examines the success of the May Revolution and the great expectations it created within and outside of the country, as well as the different phases of Nimeiry's leadership and his transformation from socialist to Islamic leader. The article emphasizes the consequences of this transformation and the subsequent fiasco of decen-

Recepción: 24 de febrero de 2015./Aceptación: 7 de julio de 2015.

*Universidad Pablo de Olavide, alfredo.langa@iecah.org 
tralization, resulting in a scenario of conflict, especially in the south of the country.

Key words: war; peace; Sudan; Nimeiry; South Sudan.

\section{Introducción}

La relación del gobierno del presidente sudanés Yaafar al Numeiri (1969-1985) con los principales actores políticos del sur del país y con sus aliados en el poder fue cambiando, lo que alteró, a la postre, el escenario del conflicto armado abierto desde la independencia del país.

Desde su acceso al control político del Estado, Numeiri basó su liderazgo en alianzas políticas que fueron evolucionando a lo largo de su periodo de gobierno, primero de la mano de los comunistas hasta abrazar las opciones islamistas. Se revisa aquí el contexto en el que se propició la firma de la paz entre el gobierno y la resistencia armada en el sur. En este sentido, los problemas que frustraron la descentralización, así como los acontecimientos que culminaron en la suspensión del proceso de paz y el deterioro de la frágil estabilidad social, son los temas que ocupan los apartados del texto, donde se analizan, acudiendo a fuentes secundarias, tanto aspectos políticos y sociales como elementos económicos y étnicos que ofrecen una visión de conjunto de los tres lustros que duró el régimen de Numeiri.

\section{La llegada al poder}

Yaafar Mohamed al Numeiri asumió el poder el 25 de mayo de 1969 apoyado por los comunistas, los Socialistas Árabes ${ }^{1}$ y los nacionalistas árabes ${ }^{2}$ y proclamando el socialismo de la Revolución de Mayo. Llegó lleno de promesas de desarrollo y de autonomía para el sur, aunque luego buscó hacerse con

${ }^{1}$ Los Socialistas Árabes fueron un grupo vinculado al partido Baaz iraquí, que en Sudán eran cercanos a los comunistas. Tim Niblock, Class and Power in Sudan. The Dynamics of Sudanese Politics, 1898-1985, Londres, MacMillan Press Lt., 1988.

${ }^{2}$ Los nacionalistas árabes constituían un conjunto de grupos difusos que se movían en torno a la sede jartumí de la Universidad de El Cairo y con ellos se relacionaban los miembros más radicales de los unionistas. Idem. 
el poder absoluto, lo que fue consiguiendo sobre todo a partir de $1977,{ }^{3}$ por ello se plantean dos etapas muy diferenciadas en su gobierno: ${ }^{4}$

- Una de revolución socialista y compromisos de desarrollo, de 1969 a 1977, durante la que proclamó que Sudán sería la "Cuba de África".

- Otra de transfiguración de la revolución socialista en una suerte de revolución islamista en una vuelta de tuerca autoritaria y centralista, de 1978 a 1985.

Numeiri llegó al poder con una visión estructuralista en lo internacional y en lo económico, y un posicionamiento de lucha revolucionaria y anticapitalista con una base claramente marxista, al menos de inicio. Sus ofrecimientos de cambio y su actitud respecto al sur despertaron el interés e incluso la admiración de analistas y políticos extranjeros, que no dudaron en ensalzar su figura y disposición, que algunos calificaron de histórica, en cuanto a las opciones que se abrían en relación con el proceso de paz. ${ }^{5}$ En su discurso de junio de 1969 dijo: "El pueblo del sur tiene el derecho de desarrollar su cultura y sus tradiciones en el marco de un Sudán unido y socialista. En consecuencia, el gobierno ha decidido reconocer al pueblo del sur el derecho a la autonomía regional en un Sudán unido". ${ }^{6}$ Como decisiones que evidenciaban esa línea política, presentó un programa de acción para cumplir ciertos requisitos que se antojaban esenciales de cara a la autonomía regional, que era vista como una meta a futuro, basado en los siguientes puntos:

- Continuación y extensión de la Ley de Amnistía.

- Desarrollo económico, social y cultural del sur.

- Formación de ciudadanos del sur para que asumieran puestos de responsabilidad en la nueva administración.

${ }^{3}$ José Luis Cortés López, Historia contemporánea de África. De Nkrumab a Mandela, Madrid, Mundo Negro, 2001.

${ }^{4}$ Mansour Khalid, The Government They Deserve. The Role of the Elite in Sudan's Political Evolution, Londres, Kegan Paul International Ltd., 1990.

${ }^{5}$ Anthony Sylvester, Sudan under Nimeiri, Londres, The Bodley Head Ltd., 1977, p. 10.

${ }^{6}$ Cortés López, Historia contemporánea de África, op. cit. 
- Creación de un consejo especial de planificación económica y de un presupuesto especial para el sur. ${ }^{7}$

Asimismo, Numeiri nombró a un comunista del sur, Joseph Garang, ${ }^{8}$ ministro de Asuntos del Sur, y a Abel Alier, del Frente Meridional, ministro de Vivienda ${ }^{9}$ sin embargo, Clement Mboro, también sudista y ministro en el gobierno anterior, fue acusado de corrupción y encarcelado por breve tiempo. ${ }^{10}$

Numeiri instauró un régimen militar socialista articulado en torno a un partido único, la Unión Socialista de Sudán (USS), y con el apoyo inicial del Partido Comunista, que presidió el Consejo del Mando Revolucionario, luego disuelto por el propio Numeiri, quien terminó asumiendo la jefatura del Estado, del gobierno y del ejército. Al inicio de su mandato contó con el respaldo soviético, lo que le permitió reforzar al ejército mediante un acuerdo militar y la compra de armamento y aviones de caza, e intensificar las operaciones militares y los combates en el sur previamente a las negociaciones de paz. ${ }^{11}$ Esta presión de los grupos rebeldes fue uno de los aspectos que finalmente lo instaron a negociar.

\section{El dominio de la uss y la ruptura con los comunistas}

La uss hizo las veces de partido único, y fue descrita como la única organización política de Sudán por la Constitución permanente de 1973, tras la aniquilación del Partido Comunista. La Uss estableció una estructura "centralista democrática”, basada en una red de "unidades básicas" que cubrían todo el país, cuyas responsabilidades estaban definidas en las "Normas básicas de la USs", entre las que figuraban: asumir el liderazgo revolucio-

${ }^{7}$ Mohamed Omer Beshir, The Southern Sudan. From Conflict to Peace, Londres, C. Hurst \& Co. Ltd., 1975.

${ }^{8}$ Joseph Garang, de la etnia luo, no tiene relación con John Garang, el futuro líder guerrillero de la etnia dinka.

${ }_{9}$ Beshir, The Southern Sudan, op. cit.

${ }^{10}$ Khalid, The Government They Deserve, op. cit.

${ }^{11}$ Jesús Díez Alcalde y Félix Vacas Fernández, Los conflictos de Sudán, Madrid, Instituto de Estudios Internacionales y Europeos "Francisco De Vitoria"-Ministerio de Defensa, 2008. 
nario y político respecto al control de las actividades diarias, vigilar la implementación de las directrices de los diversos comités de la Uss, fomentar el pensamiento socialista, solventar las necesidades de la clase trabajadora, movilizar esfuerzos de cara al incremento de la producción en todos los ámbitos, así como combatir la explotación ejercida por la clase burguesa. ${ }^{12}$

Desde el inicio de su mandato, el enfrentamiento con las hermandades sufíes tradicionales ${ }^{13}$ fue constante, por lo que los sudaneses cercanos a éstas se inconformaron. La pugna se tradujo, en un primer momento, en la expropiación y confiscación de propiedades y negocios de las familias Al Mahdi y Al Mirghani, pero el ataque a los militantes mahdistas que protestaban contra Numeiri en la isla de Aba, en marzo de 1970, sirvió como ejemplo de lo que era enfrentarse directamente al presidente. Aunque murió un gran número de seguidores de la facción del Umma del imam Al Hadi, el embate fue interpretado como una advertencia para el Partido Umma de Sadiq al Mahdi y para los unionistas de Al Mogran. ${ }^{14}$

Los intentos de presión a los líderes del sur para iniciar negociaciones y las maniobras en el seno del Consejo de la Revolución concluyeron en una intensificación del conflicto durante 1970 y 1971, debido a las acciones de los rebeldes del grupo Anya-Nya ${ }^{15}$ y su resistencia. ${ }^{16}$ En este sentido, Mohamed O. Beshir señala que el nombramiento de Joseph Garang no fue bien recibido por todos los habitantes del sur, tampoco por aquellos que vivían fuera de Sudán, y mucho menos por los que trabajaban con la Iglesia católica. La desconfianza hacia las políticas de la Revolución de Mayo y los comunistas fue constante por parte de la mayoría de los sursudaneses desde el inicio del

${ }^{12}$ Niblock, Class and Power in Sudan, op. cit., p. 204.

${ }^{13}$ Dichas cofradías eran la Jatmiyya, controlada por la familia Al Mirghani en la esfera de los partidos políticos unionistas, y la Mahdiyya, en torno al Partido Umma y a la familia Al Madi.

${ }^{14}$ Khalid, The Government They Deserve, op. cit.

${ }^{15}$ Debido a la creciente represión del gobierno de Jartum sobre la población del sur a finales de los años cincuenta y principios de los sesenta, algunos miembros de los Equatoria Corps - unidad sursudanesa del ejército- amotinados en 1955 crearon la guerrilla denominada Anya-Nya.

${ }^{16}$ Peter Malcolm Holt y Martin Daly, The History of the Sudan, Londres, The Weidenfeld \& Nicolson, 1979. 
nuevo periodo. ${ }^{17}$ La razón se encuentra en la identificación de los sudaneses del norte, árabo-musulmanes o arabizados, con la élite dominante, aunque el nuevo gobierno pretendiera romper su hegemonía y la de los intelectuales afines.

Las inestables relaciones de Numeiri con el Partido Comunista desde el inicio de su mandato se fueron agravando a lo largo de 1970 y 1971. El secretario general del Partido, Abd el Jaliq Mahjub, veía al organismo como centro del movimiento progresista sudanés y creía que debía mantener su independencia frente a los oficiales dirigentes. También pensaba que quienes apoyaban los objetivos revolucionarios tenían que agruparse en un frente democrático unido y trabajar por sus principios, pero como organizaciones autónomas, aunque esto implicara criticar al nuevo gobierno. Los oficiales, sin embargo, sintiéndose verdaderos revolucionarios y respetando el papel del Partido Comunista en el pasado, no entendían que se quisiese mantener independiente. Pensaban que tanto el Partido Comunista como el resto de las organizaciones y asociaciones habrían de disolverse para integrarse en una futura entidad unificada que se comprometiese con los postulados del socialismo. Crear un frente unido que mantuviese la autonomía de las partes aumentaría el poder del Partido Comunista respecto al del Consejo del Mando Revolucionario, debido a la influencia del primero sobre las organizaciones radicales y revolucionarias sudanesas. ${ }^{18}$

Las disputas entre militares y comunistas hallaron su punto de inflexión en el intento de apartar del poder a Numeiri mediante un golpe de Estado, que fracasó porque Egipto y Libia apoyaron al presidente, que poco a poco se hizo con todo el poder en el país. Joseph Garang fue acusado de corrupción y finalmente ejecutado en 1971, junto con otros dirigentes debido al golpe, lo cual significó el principio del fin del apoyo comunista y la sustitución de Garang por Abel Alier, del Frente Meridional, como ministro de Asuntos del Sur. ${ }^{19}$ Esto significó no sólo la ruptura definitiva con los comunistas, sino un cambio en el carácter de la Revolución de Mayo y su principal objeti-

\footnotetext{
${ }^{17}$ Beshir, The Southern Sudan, op. cit.

${ }^{18}$ Niblock, Class and Power in Sudan, op. cit.

${ }^{19}$ Beshir, The Southern Sudan, op. cit.
} 
vo: transformar la sociedad y la economía sudanesas. En su lugar, el mantenimiento de la unidad nacional y el desarrollo económico se convirtieron en las metas del régimen, y las instituciones que debían representar la voluntad popular pasaron a ser un instrumento de manipulación del poder central. ${ }^{20}$

La Revolución de Mayo de Numeiri basó su sistema político en seis elementos que fueron introducidos paulatinamente:

- El National Charter o Acta Nacional, que constituía el documento-guía de la revolución respecto a la política y la sociedad a las que aspiraba el régimen.

- Las organizaciones funcionales y populares, que fueron reajustadas para hacerlas compatibles con los objetivos del nuevo régimen.

- Los consejos locales populares, instaurados por el Acta de Autogobierno Regional o Local.

- La USS, descrita en la Constitución permanente de abril de 1972 como la única organización política sudanesa.

- El acuerdo de autonomía regional del sur de Sudán alcanzado por el Tratado de Addis Abeba de 1972.

- Las instituciones del gobierno central, entre las que destacaban la Presidencia y la Asamblea Popular.

Por otro lado, el golpe de Estado que llevó al poder a Yaafar Mohamed al Numeiri en mayo de 1969 significó una nueva fase en las estrategias económicas del gobierno de Sudán, debido al papel decisivo que una nueva coalición de fuerzas sociales tendría en el país. Ello creó grandes expectativas de desarrollo al inicio de la década de 1970 en amplios sectores de la población, que fueron alimentadas por las ambiciosas metas de los primeros planes del gobierno, aunque las dinámicas continuistas y de ruptura se sucederán durante este extenso periodo. ${ }^{21}$

Desde el punto de vista económico, se identifican tres subperiodos en los que las prioridades políticas y económicas se transmutan. En un primer momento, entre 1969 y 1972, se intenta imponer las tesis socialistas influidas por el panarabismo

${ }^{20}$ Niblock, Class and Power in Sudan, op. cit.

${ }^{21}$ Idem. 
y con el apoyo de los comunistas sudaneses al nuevo régimen. Posteriormente, entre 1972 y 1976, se deja el experimento socialista y las políticas derivan en una suerte de cruce entre la lógica de planificación y las tesis neoliberales. A partir de 1976-1977, se refuerza la tendencia neoliberal del timón político que coincide con el aumento del autoritarismo de Numeiri y el abrazo al islamismo político. En esta subetapa, entre 1976/77 y 1985, Sudán contará con apoyo de Arabia Saudita y otros países árabes a los que se acerca en un intento de romper sus vínculos internacionales tradicionales.

Dentro de este proceso, el gobierno de Numeiri fomenta las exportaciones a través de la modernización de la agricultura mediante la estrategia de granero, ${ }^{22}$ auspiciada por las necesidades alimentarias de sus nuevos socios comerciales árabes y, sobre todo, de Arabia Saudita, cuyo papel de prestamista se acentuó tras el aumento de los precios del petróleo en 1972 y con la intensificación del flujo de petrodólares en la economía mundial. Además, el alza de los precios del crudo afectó la facturación energética del país, que intentaba ejecutar su programa de desarrollo. No por ello los países occidentales dejaron de ser importantes, pues su tecnología resultaría fundamental en la estrategia de modernización, en la que las economías tradicionales sufren las peores consecuencias.

Desde el punto de vista geoestratégico, Gran Bretaña pasó el relevo a Estados Unidos como potencia colonial, aunque el hecho no conllevara un peso importante en cuanto al comercio exterior. Sudán se convirtió en receptor de la ayuda financiera norteamericana y Estados Unidos en donante, con la consecuente relación de dependencia que ello implica. En este sentido, se volvió actor clave en la estrategia anticomunista de Occidente y, sobre todo, de Estados Unidos ${ }^{23}$ en Oriente

${ }^{22}$ Dicha estrategia habría descansado en dos supuestos discutibles: la disponibilidad de tierra sin utilizar y despoblada, así como la viabilidad de la expansión de las fincas mecanizadas. Karl Wohlmuth y Dirk Hansohm, Sudan: A Case for Structural Adjustment Policies, Sudan Economy Research Group Discussion Paper núm. 8, Bremen, Universidad de Bremen, 1986.

${ }^{23}$ Sudán pasó a ser el principal beneficiario de la ayuda exterior norteamericana en el África subsahariana a inicios de los años ochenta. Alexander de Waal, Famine Crimes. Politics and the Disaster Relief Industry in Africa, Oxford-Bloomington, James Currey-Indiana University Press, 1997. 
Medio y el norte de África, por lo que no es de extrañar que hubiera un alineamiento con los islamistas, igualmente anticomunistas. Paralelamente al acercamiento del régimen de la uss a los islamistas del Frente Islámico Nacional, también asumía y trataba de aplicar las recetas del Fondo Monetario Internacional a las que los compromisos financieros adquiridos lo obligaban.

\section{El proceso de paz y el Tratado de Addis Abeba}

Después de la llegada al poder de Numeiri, se iniciaron contactos con Etiopía y Uganda, países vecinos que habían sido tradicionalmente hostiles a Sudán. Etiopía respaldaba a los separatistas Anya-Nya como respuesta al apoyo sudanés a los grupos eritreos. La Uganda de Milton Obote, por su parte, favoreció, igualmente, a los rebeldes sursudaneses. Los contactos con el Movimiento de Liberación del Sur de Sudán —surgido en 1969 de la unión de facciones de los Anya-Nya, bajo el mando del comandante Joseph Lagu - propiciaron asimismo la firma del Tratado de Addis Abeba el 27 de febrero de 1972, que daría fin a la Primera Guerra Civil, que había comenzado un año antes de la propia independencia del país. ${ }^{24}$

Mediante el Tratado, que fue incorporado como ley en el ordenamiento jurídico sudanés, se garantizaba la autonomía del sur y se aseguraba un alto al fuego bajo supervisión de la comunidad internacional. El Acta de Autogobierno Regional ${ }^{25}$ obligaba a la creación, en todo el país, de gobiernos locales más cercanos a la población, y para ello todos los gobernadores habrían de tener un origen local. ${ }^{26}$ Era el principio del denominado "sistema de gobierno local del pueblo", constituido por una pirámide formada en su base por los Consejos Populares de

${ }^{24}$ Douglas Johnson, The Root Causes of Sudan's Civil Wars, Kampala-Suffolk, Fountain Publishers-James Currey, 2011.

${ }^{25}$ El Acta de Autogobierno Regional fue la ley que desarrolló la Asamblea Regional y el Alto Consejo Ejecutivo para el sur del país. Mansour Khalid, Nimeiri and the Revolution of Dis-May, Londres, Kegan Paul International Ltd., 1985, p. 180; Khalid, The Government They Deserve, op. cit.

${ }^{26}$ Curiosamente, Darfur fue en la única región de Sudán donde esto no fue así de inicio. Gerard Prunier, Darfur. The Ambiguous Genocide, Londres, Hurst and Company Publishers, 2005. 
Pueblos y Aldeas, a los que sucedían, de manera ascendente, los Consejos Populares Rurales, así como los Consejos Populares Provinciales. ${ }^{27}$ Este sistema pretendía mejorar la presencia del pueblo en la toma de decisiones políticas, aunque en realidad sirvió para incrementar el poder de Numeiri en la cima de la pirámide. Los nuevos gobiernos locales no fueron útiles para gestionar de manera eficiente las áreas remotas del país, sino que se convirtieron en instrumento del poder central..$^{28}$

Uno de los objetivos del proceso de regionalización llevado a cabo por Numeiri en la primera parte de su mandato fue vincular la estructura de la Uss a la nueva administración local. De esta forma, el sistema de gobierno local debía alinearse con los objetivos y directrices del partido único. Esta vinculación confundió a la población, que en su mayoría no distinguía entre las unidades básicas, los consejos populares de los pueblos y las organizaciones funcionales, pues, además, las mismas personas podían representar a diversas entidades. ${ }^{29}$

En el sur, las provincias de Alto Nilo, Ecuatoria y Bahr el Ghazal formaron una entidad territorial con capital en Yuba, denominada "Región Autónoma de Sudán del Sur", que contaría con un parlamento y un Alto Consejo Ejecutivo. El acuerdo aseguraba amplias competencias en materia económica, cultural, educativa y sanitaria. El representante del sur, Abel Alier, fue nombrado vicepresidente del país y presidente del Alto Consejo; la primera Asamblea Regional fue elegida en noviembre de $1973 .{ }^{30}$ Además del Alto Consejo Ejecutivo, fueron designados varios comisarios, a modo de ministros regionales, y tres personalidades del sur fueron elegidas como ministros del gobierno central de Jartum: Lawrence Wol Wol (Planificación), Bona Malwal (Información y Cultura) y Samuel Lupai (Gobierno Local). ${ }^{31}$ Se mostraba, de esta forma, una cierta democracia dentro de la hegemonía sudanesa, lo que permitió el trasvase de algunos miembros de las élites del sur hacia pues-

${ }^{27}$ Khalid, Nimeiri and the Revolution of Dis-May, op. cit.; Khalid, The Government They Deserve, op. cit.

\footnotetext{
${ }^{28}$ Idem.

${ }^{29}$ Niblock, Class and Power in Sudan, op. cit.

${ }^{30}$ Holt y Daly, The History of the Sudan, op. cit.

${ }^{31}$ Beshir, The Southern Sudan, op. cit.
} 
tos de responsabilidad en el gobierno central con la confirmación del presidente de Sudán. Igualmente, la Asamblea podría plantearle a éste que no se aplicaran leyes que menoscabaran los intereses del sur..$^{32}$

Los principales términos del Tratado incorporaban la idea de un Sudán unido y la creación de un gobierno representativo del sur, con ingresos destinados a la gestión del autogobierno y su desarrollo económico, así como a la seguridad regional en manos de sursudaneses. En este sentido, las Fuerzas Armadas Populares del sur se integrarían al Comando Meridional compuesto por 12000 soldados y oficiales, de los cuales 6000 debían ser ciudadanos de la región. Este punto no resultó de fácil ejecución, pues muchos antiguos guerrilleros, sobre todo pertenecientes al Anya-Nya, decidieron no incorporarse al nuevo ejército y se marcharon a Etiopía principalmente. Además, mientras que la cuota de 6000 soldados meridionales se cumplió, el número de soldados norteños no se redujo a ese número. ${ }^{33}$

El Tratado de Addis Abeba no contó con el apoyo de los partidos árabes del norte, ni laicos ni islámicos, lo que provocó la paulatina degradación de las relaciones norte-sur y el incumplimiento del acuerdo. La oposición no fue sólo interna, también la Libia del coronel Gadafi se opuso al Tratado por considerar que impedía una futura alianza entre Libia y el norte de Sudán, por lo que, sorpresivamente, instó a la secesión del sur..$^{34}$ De esta manera, los compromisos agonizaron y, con ellos, las esperanzas de autonomía del sur, que fueron enterradas en 1983, cuando la Región Autónoma fue abolida por el gobierno del propio Numeiri.

\section{La descomposición del Tratado de Addis Abeba y la deriva islamista de Numeiri}

El gobierno de Numeiri despertó grandes expectativas por su carácter secular y sus promesas de cambio, libertad y desarrollo,

\footnotetext{
${ }^{32}$ Johnson, The Root Causes of Sudan's Civil Wars, op. cit.

33 Idem.

${ }^{34}$ Khalid, The Government They Deserve, op. cit.
} 
por lo menos hasta 1975, pues como Mansour Khalid señala, el "filósofo presidente" terminó convirtiéndose en el "imam presidente". ${ }^{35}$ Del mismo modo, la arena política pasó de ser el lugar donde se debatían los problemas del país para buscarles solución, a ser el escenario donde Numeiri representaba su "espectáculo" y trataba de distraer a la población de las dificultades inmediatas que la aquejaban. ${ }^{36}$

El deterioro de la situación vino de la mano del mal gobierno y del autoritarismo, y la creciente corrupción política y económica se convirtió en "el elemento más corrosivo de la vida pública sudanesa”. ${ }^{37}$ La Constitución permanente de 1973, que proporcionó un marco legal de gobierno y otorgaba amplios poderes al presidente, integró y salvaguardó los términos firmados en Addis Abeba. Entre los aspectos más importantes para garantizar la paz, esta Constitución establecía el derecho a la libertad de culto en la totalidad del territorio sudanés y un Estado secular que, posteriormente, chocarían con las aspiraciones de Numeiri y sus aliados de aplicar la sharía. ${ }^{38}$ Varios factores minaron las expectativas creadas: la inestabilidad política y los intentos de golpe de Estado, que llevaron a un acercamiento de Numeiri a la oposición del norte; la masiva emigración de profesionales a los estados del Golfo, así como el fracaso de su política económica de apertura que lo aproximó, simultáneamente, al Fondo Monetario Internacional y a los islamistas. ${ }^{39}$

En el norte, el gobierno tuvo la oposición de los ansar del Umma, de los unionistas y de los Hermanos Musulmanes, que tomaron las calles de las ciudades del norte y provocaron graves enfrentamientos con las fuerzas de seguridad y con sus seguidores. Además, la actitud de Numeiri ante la situación en Chad y la cercanía con su gobierno provocaron una virulenta reacción de Gadafi, que equipó a las milicias contra Sudán. ${ }^{40} \mathrm{El}$ hecho de que Numeiri apoyase la autonomía del sur fue visto

${ }^{35}$ Idem.

${ }^{36}$ Niblock, Class and Power in Sudan, op. cit.

${ }^{37}$ Khalid, The Government They Deserve, op. cit., p. 2.

${ }^{38}$ Johnson, The Root Causes of Sudan's Civil Wars, op. cit.

39 De Waal, Famine Crimes, op. cit.

${ }^{40}$ Unos 1200 milicianos equipados y entrenados por Libia llegaron a tomar Jartum en 1976, aunque fueron rechazados y vencidos por las tropas del gobierno. Prunier, Darfur. The Ambiguous Genocide, op. cit. 
con recelo por casi la totalidad de las organizaciones del norte. Al mismo tiempo, las buenas relaciones con Estados Unidos e Israel crearon malestar no sólo en Sudán, sino también en los países árabes. ${ }^{41}$ Es importante señalar que eran los tiempos de la Guerra Fría, y Sudán constituía una pieza clave de la estrategia anticomunista de Estados Unidos en África y Medio Oriente, al igual que los Hermanos Musulmanes, también anticomunistas, por lo que Sudán se convirtió en el principal receptor de ayuda exterior de aquel país en el África subsahariana a principios de la década de 1980.42

La presión social obligó a Numeiri a reunirse con Sadiq al Mahdi, líder del Umma, y a enviar señales al resto de la oposición, que cristalizaron en la declaración de una amnistía general y reconciliación nacional y la integración de algunos de sus líderes al gobierno y a la Asamblea Popular tras las elecciones de 1978. Esto incluyó a los islamistas, que vieron cómo su dirigente, Hassan al Turabi, ${ }^{43}$ pasaba de la cárcel donde se hallaba en 1977 a ostentar el cargo de fiscal general en abril de 1978, en un alarde de "flexibilidad" por parte de Turabi. ${ }^{44}$ Eso dio al traste con las proclamas del gobierno secular de que quería construir un Estado basado en la ciudadanía y no en la religión ${ }^{45}$ y ponía en grave peligro la Constitución permanente, basada en la libertad de culto y en lo firmado en la capital de Etiopía.

Previamente, Numeiri se aseguró de nuevo la Presidencia del país, tras la convocatoria del Congreso Nacional de la Uss en enero de 1977, donde fue elegido como su dirigente, lo cual equivalía a ser presidente de Sudán. ${ }^{46}$ La elección, según Mansour Khalid, no fue todo lo limpia que se esperaba y Numeiri

${ }^{41}$ James Millard Burr y Robert Collins, Revolutionary Sudan. Hasan al-Turabi and the Islamic State, 1989-2000, Leiden, Brill, 2003, pp. 94-95.

${ }^{42}$ De Waal, Famine Crimes, op. cit.

${ }^{43}$ Para justificar esta alianza, Turabi se remitió al denominado "paradigma de José” en la sura 12 del Corán, que explica, según él, cómo trabajar para el Estado y contra el Estado al mismo tiempo. Abdullahi Ibrahim, "A Theology of Modernity: Hasan al-Turabi and Islamic Renewal in Sudan”, Africa Today, vol. 46, núm. 3/4, 1999, pp. 208-214.

${ }_{44}$ "Para él, los medios siempre justificaban el fin: un Estado islámico". Julie Flint y Alexander De Waal, Historia breve de una larga guerra, Barcelona, Intermón Oxfam Ediciones, 2007, p. 30.

${ }^{45}$ Khalid, The Government They Deserve, op. cit.

${ }^{46}$ Idem. 
manipuló a sus seguidores para que le mostraran su apoyo en las calles y luego declarar: "Acepto porque es la voluntad de las masas". ${ }^{47}$

Numeiri pensó que integrar a Al Mahdi y Turabi a los órganos del poder era la mejor manera de acabar con los sectarismos tradicionales del norte, habida cuenta de los intentos de golpe de Estado sufridos en 1975 y 1976. De esta manera, la oposición quedó reducida a las organizaciones del sur, las asociaciones profesionales y los sindicatos, así como a los Hermanos Republicanos liderados por Mahmoud Mohamed Taha, ${ }^{48}$ firmes defensores de la democracia en Sudán y de un modelo económico redistributivo que favoreciese la equidad, factor que los llevó a ser reprimidos y a la clandestinidad. Taha representaba un peligro como intelectual que pretendía reformar las bases de la superestructura vigente en el norte de Sudán y que trataban de imponer en el sur, por lo que las élites hegemónicas pidieron su eliminación.

El sistema de gobierno fue degenerando en una burocracia corrupta de la que incluso cierta oposición se nutría y que era aprovechada no sólo en Jartum, sino igualmente en las regiones. La corrupción se volvió endémica y se generalizó de todas las formas posibles, a tal grado que algunos sectores cercanos al poder amasaron fortunas y propiedades, mientras los servicios públicos agonizaban y los ciudadanos despertaban del sueño de la "opulencia estatal" de principios de los años setenta. ${ }^{49}$ La necesidad de mantener ese sistema corrupto y burocrático en torno a la USS y a la figura de Numeiri fue esencial para el cambio de rumbo que supusieron las Leyes de Septiembre y que confirmaron el giro islamista de la política sudanesa. Con la excusa de reemplazar un sistema legal de herencia colonial y una serie de leyes y órdenes provisionales, se permitió, de ma-

${ }^{47}$ Citado por Khalid, Nimeiri and the Revolution of Dis-May, op. cit., p. 204.

${ }^{48}$ Los Hermanos Republicanos y su partido político, el Partido Republicano, fueron liderados por el ustadb o maestro Mahmoud Mohamed Taha, que desde posiciones pacifistas planteaba una interpretación del islam integradora y abierta al resto de las religiones del país, en la que los derechos humanos y la igualdad de sexos jugaban un importante papel. Taha fue acusado de apostasía y ahorcado públicamente por órdenes de Numeiri el 18 de enero de 1985. Khalid, The Government They Deserve, op. cit.

${ }^{49}$ Idem; De Waal, Famine Crimes, op. cit. 
nera progresiva, la instauración de la ley islámica en Sudán a finales de 1983.50

La influencia de los Hermanos Musulmanes, y de su rama sudanesa encabezada por Turabi, se hizo palpable con este golpe de timón que afectaría las relaciones norte-sur y sería uno de los factores esenciales para reavivar la guerra civil. La creación del Frente Islámico Nacional como organización vertebral de los Hermanos Musulmanes supuso la aparición de una agenda de islamización de Sudán justificada en sus directrices políticas, ${ }^{51}$ en las que se subrayaba que el secularismo no era propio de la sociedad sudanesa, pues los musulmanes tenían derecho legítimo - en virtud de la práctica de la libertad religiosa, de su peso demográfico y de la justicia natural- a practicar los valores y normas de su religión en cualquiera de sus esferas, ya sea la personal, la social o la política. ${ }^{52}$ De esta manera, las élites islamistas comenzaron su tarea de transformación de la superestructura, que hasta entonces había sido modelada por los intelectuales, básicamente, en torno a las cofradías tradicionales y los partidos políticos mahdistas y unionistas.

Los comerciantes islamistas y los bancos islámicos lograron el control de la economía a través de los sectores que dependían de las remesas de los emigrantes. Más aún, la compra de tierras y fincas, así como de empresas de transportes y de antiguas propiedades estatales, confirió un matiz económico al creciente poder islamista. Se diría que Sudán fue comprado y vendido durante estos años. ${ }^{53}$

La amnistía general y la reconciliación nacional posibilitaron la introducción del movimiento islamista entre las organizaciones sociales sudanesas y la sociedad civil en general. A pesar de ello, la relación de Numeiri con los islamistas, y sobre todo con los Hermanos Musulmanes, continuó siendo difícil, ya que su actividad semiclandestina, anterior a 1977, pasó a ser pública y se abrió a todos los grupos sociales, con lo que perdió

${ }^{50}$ Cortés López, Historia contemporánea de África, op. cit.

${ }^{51}$ Estas directrices se incluyeron en Sudan Charter, National Unity and Diversity, publicado por el Frente Islámico Nacional en 1987. Carolyn Fluehr-Lobban, Richard A. Lobban y John Obert Vollet, Historical Dictionary of the Sudan, $2^{\mathrm{a}}$ ed., Londres, The Scarecrow Press, Inc., 1992.

${ }^{52}$ Cortés López, Historia contemporánea de África, op. cit.

${ }^{53}$ De Waal, Famine Crimes, op. cit. 
su carácter elitista. ${ }^{54}$ Asimismo, la base social del régimen se fue reduciendo y prominentes líderes regionales y locales del norte y del sur se fueron desligando del gobierno de la Unión Socialista de Sudán. ${ }^{55}$

En el sur, la organización al Dawa al Islamiyya, creada en 1979, fue la primera referencia importante del proyecto islamista que pretendía atraer a los sursudaneses hacia un Estado islámico unido, aunque respetando, inicialmente, la diversidad étnica y religiosa. Se trataba de proteger a la población musulmana del sur y de reforzar la presencia del islam allí mediante la promoción de obras de caridad entre la población no musulmana. Por un lado se quería aumentar la base social en el sur $y$, por otro, contrarrestar la presencia de las organizaciones no gubernamentales occidentales. ${ }^{56}$

En septiembre de 1983, el presidente Numeiri anunció que los castigos tradicionales islámicos contenidos en la sharía pasarían a formar parte del Código Penal sudanés, lo cual fue controvertido incluso entre los propios musulmanes. El caso más extremo se consumó con el ahorcamiento, en enero de 1985, del líder pacifista religioso y cabeza de los Hermanos Republicanos, Mahmoud Mohamed Taha, contrario a la aplicación de la ley islámica en el país y partidario del diálogo con el sur. Uno de los compañeros de Taha, Abdullahi Ahmed An Naim, ${ }^{57}$ no tiene dudas respecto a que la presión ejercida por los preceptores ortodoxos del Departamento Sudanés de Asuntos Religiosos, los líderes de las sectas tradicionales, así como por los Hermanos Musulmanes sudaneses, fue una de las principales razones que empujaron a Numeiri a tomar la decisión de ejecutar al ustadh.

Para Mansour Khalid, ${ }^{58}$ además de los argumentos oportunistas e inmediatos que Numeiri esgrimió para llevar a cabo la islamización, hubo diversos aspectos que precipitaron la

\footnotetext{
${ }^{54}$ Rafael Ortega Rodrigo, El movimiento islamista sudanés. Discursos, estrategias y transformaciones, Alcalá la Real, Alcalá Grupo Editorial, 2010, pp. 43-46.

${ }^{55}$ Idem.

${ }^{56}$ Ortega Rodrigo, El movimiento islamista sudanés, op. cit.

${ }^{57}$ Abdullahi An Naim, “Translator's Introduction”, en Mahmoud Mohamed Taha, The Second Message of Islam, Siracusa, Syracuse University Press, 1987, pp. 1-4.

${ }^{58} \mathrm{Khalid}$, Nimeiri and the Revolution of Dis-May, op. cit.
} 
decisión con miras al futuro. Por un lado, su política lo situaba cercano a los seguidores de los ansar y la Jatmiyya, y por lo tanto de los Al Mirghani y el Umma, así como de Turabi y los suyos. El liderazgo político-militar dio paso a uno religioso que desvió la atención del colapso de los servicios públicos y el mal gobierno hacia los "pecados" de los ciudadanos, alejando el punto de mira de la corrupción gubernamental para fijarlo en la conducta personal. De esta manera, "haciendo de la sharía, según la interpretación de Numeiri y sus vicarios, la ley del país, la mayoría de los sudaneses se convirtieron en pecadores sin dios". ${ }^{59}$

\section{La vuelta a las hostilidades entre el norte y el sur}

Según Khalid, ${ }^{60} 1983$ marcó un hito en la política sudanesa, ya que Numeiri llevó a cabo tres autogolpes de Estado que se sumaron a la introducción de la sharía e influyeron decisivamente en la reactivación y la escalada del conflicto armado. En primer lugar, la toma del poder en el seno de la uss fue progresiva, al apartar a ministros y desactivar la acción del gobierno para acumular gradualmente todo el poder en la Presidencia. Para compensar su aislamiento, se estrecharon las relaciones con Estados Unidos, Egipto e Israel, países a los que incluso permitió el establecimiento de bases militares en territorio sudanés, lo que provocó fuertes presiones del norte y, desde el exterior, por parte de los países árabes.

El segundo golpe de Estado fue el perpetrado contra el sur, al demoler el Tratado de Addis Abeba y arruinar las esperanzas de paz. Su propuesta de división regional para hacer de Sudán "uno de los países más descentralizados del mundo" contribuyó decisivamente a ello. Con esta partición Sudán quedaba, irónicamente, fragmentada en las mismas ocho administraciones que los británicos habían establecido en su antigua colonia. ${ }^{61} \mathrm{~A}$ esto se sumó la imposición de la sharía a través de las Leyes de

\footnotetext{
${ }^{59}$ Idem.

${ }^{60}$ Idem.

${ }^{61}$ Khalid, The Government They Deserve, op. cit., p. 239.
} 
Septiembre de 1983, que no fueron sino el apogeo del proceso contra el sur y lo que terminó provocando el levantamiento armado y la reanudación de la guerra.

El último golpe de Estado, según Mansour Khalid, fue perpetrado contra el estamento judicial al acusarlo de ineficiente y culpar a unos 50 jueces de corrupción. Esto significó el fin del intento de independencia de los jueces, que aunque durante un tiempo midieron fuerzas con Numeiri, se vieron desbordados con la aplicación de la sharía. ${ }^{62}$

Además de la islamización y la destrucción del Estado secular, así como del proceso de regionalización impuesto, otros factores fueron esenciales para entender el rechazo del sur a la política de Numeiri, así como para explicar el porqué de su metamorfosis islamista: el deficiente manejo de la economía nacional y meridional y el intento de ejecutar dos ambiciosos proyectos de desarrollo e infraestructura: la construcción del canal de Jonglei y la explotación de los campos petrolíferos de Bentiu. ${ }^{63}$

El canal de Jonglei planteaba una construcción de $360 \mathrm{~km}$ en la región del Alto Nilo para desviar la corriente del río para suministrar agua a Egipto y Sudán, lo que evitaría, además, las pérdidas de agua que provocaban las crecidas. El proyecto afectaba, principalmente, las tierras habitadas por los dinkas, que no fueron informados de las ventajas ni de cómo influiría el canal en las economías locales de subsistencia, lo que provocó el rechazo de la población.

Por otra parte, el hallazgo de petróleo en el sur por parte de la empresa Chevron Oil Company of Sudan, ${ }^{64}$ en 1978, acrecentó las reticencias del norte hacia la autonomía del sur, cuya Asamblea fue derogada en 1981. Más aún, el vicepresidente Alier fue sustituido por un musulmán; en 1983 se declaró que el árabe sería el idioma oficial de nuevo y se abolió la autonomía, por lo que el control de las fuerzas armadas del sur regresó al norte. ${ }^{65} \mathrm{El}$ petróleo hallado en la franja norte de Bahr el Ghazal hizo de Bentiu un símbolo de la "armonía” norte-sur y llevó

\footnotetext{
${ }^{62}$ Khalid, Nimeiri and the Revolution of Dis-May, op. cit.

${ }^{63}$ Khalid, The Government They Deserve, op. cit.

${ }^{64}$ Ésta era filial de la American Standard Oil of California Corporation.

${ }^{65}$ Khalid, Nimeiri and the Revolution of Dis-May, op. cit.
} 
a los líderes de ambas partes a darse cuenta de que quien controlara el crudo, dominaría la región. El petróleo garantizaría la seguridad y el bienestar de quien lo gestionase y, de cara al gobierno, podría ser un importante factor de estabilidad para la maltrecha economía sudanesa, aunque pronto se convirtió en lo contrario. ${ }^{66}$

Ambos proyectos se volvieron objetivos de los rebeldes meridionales y foco de tensión durante la Segunda Guerra Civil sudanesa, que se inició, como la primera, tras el motín de las tropas sureñas. Todos estos elementos, reunidos en torno a la creciente islamización del norte bajo la influencia de los Hermanos Musulmanes de Egipto y su aliado en Sudán, Hassan al Turabi, desembocaron en una lucha que duraría veinte años. Paradójicamente, este acercamiento a cierta interpretación de la religión islámica de Numeiri y su régimen lanzó a Sudán al abismo de la guerra y liquidó las esperanzas de paz, lo que contrasta con la visión del malogrado Mohamed Taha, quien consideró que el acercamiento a otra interpretación del islam habría llevado al país por la senda de la armonía.

\section{El fin de Numeiri y el reinicio de la guerra civil}

Numeiri hizo algunos intentos de negociación con el Movimiento/Ejército de Liberación del Pueblo de Sudán (M/ELPS) durante 1984 y 1985, mientras la sharía se aplicaba con severidad por todo el país, sobre todo entre los no musulmanes. Ofreció a Garang la vicepresidencia de Sudán y varios ministerios a algunos de sus aliados a través de un mediador, pero la propuesta fue rechazada con vehemencia. ${ }^{67} \mathrm{El} \mathrm{M} / \mathrm{ELPS}$ continuó con una dura campaña militar en Jonglei y el Alto Nilo principalmente, que combinaba con secuestros de funcionarios de altos cargos políticos y militares del régimen de Jartum, así como del personal de empresas nacionales e internacionales. Al mismo tiempo, la oposición del norte se acercó al M/ELPS pues su exis-

${ }^{66}$ Jemera Rone, "Sudan: Oil \& War", Review of African Political Economy, vol. 30, núm. 97, septiembre de 2003, pp. 504-510.

${ }^{67}$ Khalid, Nimeiri and the Revolution of Dis-May, op. cit. 
tencia significaba que Numeiri había perdido la confianza de los sursudaneses, conseguida tras la firma del Tratado de Addis Abeba, y porque un acuerdo entre Jartum y el M/ELPs habría dado oxígeno al gobierno para continuar algún tiempo más, lo que no era de su agrado. Por todo ello, el acercamiento de los opositores de ambos bandos se materializó en varios encuentros, como el auspiciado por el coronel Gadafi ${ }^{68}$ en Trípoli, en diciembre de 1984, o las reuniones en Etiopía que culminaron en la Declaración de Koka Dam. ${ }^{69}$

El último intento de Numeiri de alcanzar un acuerdo con el M/ELPs llegó con una propuesta de alto al fuego y el inicio de un proceso de paz - aprovechando la visita del entonces vicepresidente de Estados Unidos, George Bush, en marzo de 1985-, la cual fue rechazada por John Garang, aduciendo los compromisos incumplidos en el pasado por Numeiri. Garang hizo una lista que ilustra la decadencia del poder de Numeiri y su inclinación hacia la dictadura: había aceptado un matrimonio de conveniencia con la uss y los comunistas, a los que terminó persiguiendo; pactó con los Hermanos Republicanos y acabó ejecutando a su líder, Mahmoud M. Taha; firmó, y posteriormente derogó, el Tratado de Addis Abeba con lo que ello significaba para el sur; llegó a un acuerdo con el partido Umma de Sadiq al Mahdi y años más tarde lo encarceló; finalmente, apoyó a los Hermanos Musulmanes para romper con ellos al final de su mandato. ${ }^{70}$

De esta manera, el inicio de conversaciones con la guerrilla del sur y las desavenencias en el seno de la coalición propiciaron una situación de inestabilidad, empeorada por las presiones de los grupos más extremistas del norte. Es importante enfatizar que el régimen de Numeiri no se volvió despótico y opresivo de la noche a la mañana; su progresiva deriva autoritaria provino tanto del apoyo de los Hermanos Musulmanes como del beneplácito pasivo de otras fuerzas políticas, lo que permitió la instauración de la sharía por decreto y que Numeiri

${ }^{68}$ Gadafi acogió a la oposición y, posteriormente, apoyó militarmente a Numeiri, incluso de manera directa al participar en los ataques al sur. Khalid, The Government They Deserve, op. cit.

${ }^{69}$ Idem. 
condujera al país a una nueva guerra civil como consecuencia de un largo proceso de erosión y decadencia. ${ }^{71}$

Los factores mencionados hicieron que Numeiri fuese perdiendo apoyo social y que las protestas se generalizaran. Asimismo, la hambruna de 1983-1985, negada reiteradamente por Jartum, fue utilizada por sus adversarios y sirvió para desgastar la cohesión en el seno de la uss. Como apunta Alex de Waal: "La caída de Numeiri fue el triunfo de la politización de la hambruna" ${ }^{72}$

La inestabilidad y la tensión política y social culminarían con el golpe de Estado perpetrado por su ministro de Defensa y comandante en jefe de las Fuerzas Armadas, Abderrahman Sewar al Dahab, el 6 de abril de 1985, aprovechando un viaje de Numeiri a Estados Unidos, y con él se instauró un Consejo Militar Transitorio.

\section{Conclusiones}

De la mano de las tesis marxistas y un socialismo construido desde el poder sin bases sociales firmes, la estructura creada por el gobierno de Numeiri se derrumbó con la aparición de las primeras fisuras con sus socios comunistas. En un principio, la revolución liderada por él trajo una agenda política de base socialista que planteaba un ambicioso programa de reformas para reestructurar la economía y la sociedad sudanesas y enfrentarse al statu quo imperante. Dicho desafío se materializó en el Acta Nacional, que constituyó el documento-guía. Sin embargo, la dura oposición de las élites dominantes y los grupos hegemónicos, unida a las crecientes divisiones internas dentro del movimiento revolucionario desde los primeros pasos, impidieron la implementación del giro socialista, que sobreviviría apenas dos años al carecer de una base social amplia y resultar de carácter tecnocrático, desarrollado desde la dirigencia y no desde la sociedad, por lo que sucumbió a los envites de las élites tradicionales. Al mismo tiempo, la inexistencia de un Es-

\footnotetext{
${ }^{71}$ An Naim, “Translator's Introduction”, op. cit.; Johnson, The Root Causes of Sudan's Civil Wars, op. cit.

72 De Waal, Famine Crimes, op. cit., p. 92.
} 
tado fuerte, necesario para construir un sistema "a la soviética”, añadió debilidad al nuevo régimen.

La breve experiencia socialista perdería su base ideológica y teórica con el giro hacia cierto capitalismo de Estado, al que fue orillada por las directrices impuestas por los poderes financiero, comercial y monetario que representaban los organismos internacionales, y que constataría que la estructura económica y social heredada del periodo colonial había sobrevivido a los cambios introducidos por Numeiri y vencido su timorato ejercicio de contrahegemonía, y para ello fue decisiva la resistencia de las élites tradicionales en torno a los partidos mahdistas y unionistas.

A partir de 1973, la política de Numeiri estaría marcada por las consecuencias del intento de golpe de Estado de sus aliados comunistas que, a la postre, llevó a la consolidación de una burguesía burocrática dirigente, apoyada en la uss como única fuerza política del país. De esta manera, en el seno de la sociedad sudanesa gobernada por la Uss, se gestó una suerte de nueva burocracia, a la vez que aumentaba el poder de ciertos militares y, sobre todo, del círculo más cercano a Numeiri. Así se consuma un proceso de hibridación entre socialismo de Estado y cierto neoliberalismo panarabista durante los años setenta.

Para la economía sudanesa, el éxito inicial y posterior fracaso de la estrategia de granero significó un importante desequilibrio en la balanza de pagos y una creciente necesidad de financiación exterior. La deuda lastró las esperanzas de relanzar el crecimiento económico y evidenció los problemas financieros del país. Por esta razón, Numeiri fue asumiendo compromisos y recomendaciones de los organismos financieros multilaterales, a la vez que se acercaba a los islamistas desde el punto de vista social y político, consciente de que una economía islamista paralela se estaba introduciendo en el país a través de organizaciones islamistas internacionales, al tiempo que la entrega de la banca nacionalizada a manos de los bancos islámicos reforzaba el papel del nuevo actor. Esto trajo consigo el fin del discurso originario de Numeiri, quien había prometido hacer de Sudán la Cuba de África, para tornar su retórica en una falsa diatriba social mientras el islamismo y el neoliberalismo entraban con fuerza en la economía y la sociedad sudanesas, am- 
bos mediante la imposición; el primero introduciendo, con las Leyes de Septiembre y la represión, una superestructura que modificaba el islam tradicionalmente practicado en Sudán, y el segundo aplicando las recetas del Consenso de Washington. ${ }^{73}$

Al mismo tiempo, los problemas económicos de inicios de los años ochenta fueron decisivos para el desarrollo de las dinámicas que permitieron que resurgiera el conflicto en el sur, ya que fue allí donde los efectos de la crisis se sintieron con mayor intensidad. Los fondos destinados a la regionalización y a las instituciones del sur escasearon, sobre todo porque el gobierno regional meridional no fue más que una delegación del gobierno de Jartum sin apenas capacidad de decisión en cuanto a planificación económica. Esto evidenciaba el carácter periférico de la economía sursudanesa respecto al norte, que constituía su centro, aunque al mismo tiempo ésta era la periferia de las economías centrales. Tras el breve sueño del inicio del gobierno de Numeiri, el carácter de periferia extractiva de la economía del norte respecto al exterior se hizo más evidente, así como el de la economía del sur respecto a la del norte. En este sentido, el cambio de timón hacia el islamismo vendría, según Khalid, acompañado de la falta de políticas económicas eficientes para el sur, así como de la necesidad de controlar amplias áreas del territorio meridional, ${ }^{74}$ específicamente en los estados del Alto Nilo y Unity, debido a la construcción del canal de Jonglei y a la exploración de los yacimientos de crudo de Bentiu, respectivamente, que pronto se convertirían en objetivo del $\mathrm{M}$ / ELPS. ${ }^{75}$ Por ello, el aumento de la ayuda exterior fue un factor que acentuó la violencia en el país.

La deficiente planificación económica se identifica como una de las causas fundamentales del fracaso de las políticas de los gobiernos de Numeiri, a pesar de los programas y planes lan-

${ }^{73}$ Además, la compra de terrenos, tierras de cultivo, empresas de transporte y de propiedades fruto de la privatización del Estado aumentó el peso islamista en la economía sudanesa. Ortega Rodrigo, El movimiento islamista sudanés, op. cit.; De Waal, Famine Crimes, op. cit.

${ }^{74}$ Khalid, The Government They Deserve, op. cit.; Khalid, Nimeiri and the Revolution of Dis-May, op. cit.; Niblock, Class and Power in Sudan, op. cit.

${ }^{75}$ Harry Verhoeven, "Climate Change, Conflict and Development in Sudan: Global Neo-Malthusian Narratives and Local Power Struggles”, Development and Change, vol. 42, núm. 3, mayo de 2011, pp. 679-707. 
zados, ya que muchas iniciativas y proyectos se adoptaron de manera ad hoc y no en función de dicha planificación. Más aún, algunas decisiones de gasto o de financiación fueron negociadas directamente por ministros o altos funcionarios sin consulta previa al organismo de planificación central, lo que perjudicó las acciones previstas no sólo por la deficiente gestión, sino también por la corrupción creciente en el seno de la administración.

La inestabilidad política fue en aumento, y el resurgir de la resistencia organizada en el sur, personificada en el M/ELPS, se hizo notar. De esta forma, la crisis económica desembocó en una crisis política y, recíprocamente, ésta dio cuenta de la maltrecha economía, en un ciclo perverso alimentado por la aguda sequía de 1984-1985. ${ }^{76}$ Estas circunstancias favorecieron la génesis de la grave inseguridad alimentaria y el hambre en las zonas fronterizas entre el norte y el sur. El sueño de un desierto verde se tornaría espejismo y pesadilla con la hambruna.

Dirección institucional del autor:

Alice Salomon Hochschule Berlin

Alice-Salomon-Platz 5

12627, Berlin, Germany

\section{Bibliografía}

AN NAIM, Abdullahi, “Translator's Introduction”, en Mahmoud Mohamed Taha, The Second Message of Islam, Siracusa, Syracuse University Press, 1987, pp. 1-4.

Beshir, Mohamed Omer, The Southern Sudan. From Conflict to Peace, Londres, C. Hurst \& Co. Ltd., 1975.

Burr, James Millard y Robert Collins, Revolutionary Sudan. Hasan al-Turabi and the Islamic State, 1989-2000, Leiden, Brill, 2003.

CorTÉs LóPEZ, José Luis, Historia contemporánea de África. De Nkrumah a Mandela, Madrid, Mundo Negro, 2001.

De WaAl, Alexander, Famine Crimes. Politics and the Disaster Relief Industry in Africa, Oxford-Bloomington, James Currey-Indiana University Press, 1997.

Díez Alcalde, Jesús y Félix Vacas Fernández, Los conflictos de Su-

${ }^{76}$ Khalid, The Government They Deserve, op. cit. 
dán, Madrid, Instituto de Estudios Internacionales y Europeos "Francisco De Vitoria"-Ministerio de Defensa, 2008.

FLINT, Julie y Alexander de Waal, Historia breve de una larga guerra, Barcelona, Intermón Oxfam Ediciones, 2007.

Fluehr-Lobban, Carolyn, Richard A. Lobban y John Obert Voll, Historical Dictionary of the Sudan, $2^{\mathrm{a}}$ ed., Londres, The Scarecrow Press, Inc., 1992.

Frente Islámico Nacional, Sudan Charter, National Unity and Diversity, Jartum, enero de 1987.

Holt, Peter Malcolm y Martin Daly, The History of the Sudan, Londres, The Weidenfeld \& Nicolson, 1979.

IвrAнiм, Abdullahi, "A Theology of Modernity: Hasan al-Turabi and Islamic Renewal in Sudan", Africa Today, vol. 46, núm. 3/4, 1999, pp. 208-214.

Johnson, Douglas, The Root Causes of Sudan's Civil Wars, KampalaSuffolk, Fountain Publishers-James Currey, 2011.

KHALID, Mansour, Nimeiri and the Revolution of Dis-May, Londres, Kegan Paul International Ltd., 1985.

KHALID, Mansour, The Government They Deserve. The Role of the Elite in Sudan's Political Evolution, Londres, Kegan Paul International Ltd., 1990.

Niblock, Tim, Class and Power in Sudan. The Dynamics of Sudanese Politics, 1898-1985, Londres, MacMillan Press Lt., 1988.

Ortega Rodrigo, Rafael, El movimiento islamista sudanés. Discursos, estrategias y transformaciones, Alcalá la Real, Alcalá Grupo Editorial, 2010.

Prunier, Gerard, Darfur. The Ambiguous Genocide, Londres, Hurst and Company Publishers, 2005.

Rone, Jemera, "Sudan: Oil \& War", Review of African Political Economy, vol. 30, núm. 97, septiembre de 2003, pp. 504-510.

Sylvester, Anthony, Sudan under Nimeiri, Londres, The Bodley Head Ltd., 1977.

Verhoeven, Harry, "Climate Change, Conflict and Development in Sudan: Global Neo-Malthusian Narratives and Local Power Struggles", Development and Change, vol. 42, núm. 3, mayo de 2011, pp. 679-707.

Wohlmuth, Karl y Dirk Hansohm, Sudan: A Case for Structural Adjustment Policies, Sudan Economy Research Group Discussion Paper núm. 8, Bremen, Universidad de Bremen, 1986. 
